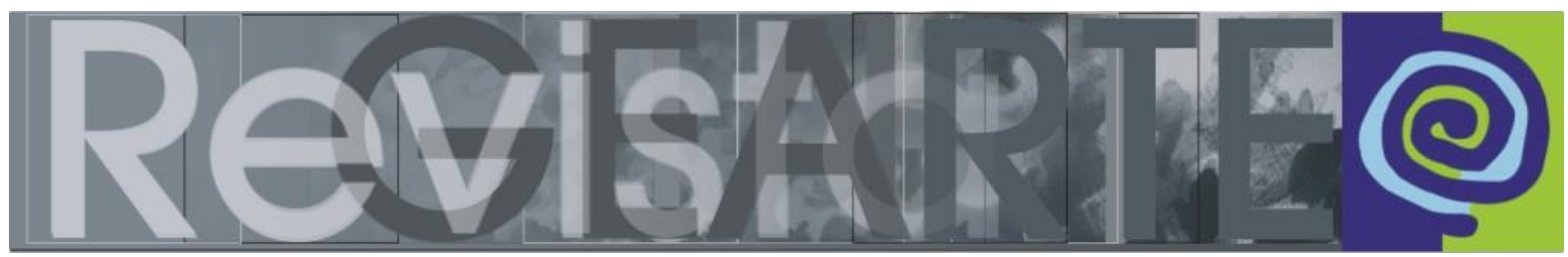

e-ISSN 2357-9854

\title{
Ensino de arte na perspectiva da Somaestética
}

\author{
Luciana Mourão Arslan (Universidade Federal de \\ Uberlândia - UFU, Uberlândia/MG, Brasil)
}

\begin{abstract}
RESUMO - Ensino de arte na perspectiva da Somaestética - O artigo apresenta uma proposta de metodologia de Ensino de Arte de Artes Visuais que considera como fundamental os aspectos somáticos (corporais). Esta proposta, a Somaestética, retoma a ideia da Estética como ciência dedicada às dimensões sensoriais e atualiza a concepção de "experiência" de Dewey(1859-1952).A reflexão sobre a experiência estética, a partir da perspectiva da Somaestética, propicia que estudantes e professores valorizem opções culturais e artísticas mais amplas - considerando as experiências estéticas mais próximas da vida cotidiana e que se relacionam com prazeres corporais.
\end{abstract}

PALAVRAS-CHAVE

Corpo. Soma. Somaestética. Ensino de arte. Experiência estética.

RESUMEN - Enseñanza de las Artes Visuales en la perspectiva de la Somaestética - El trabajo presenta una propuesta de metodología de enseñanza de las Artes Visuales que considera como fundamental los aspectos somáticos (corporales). La Somaestética retoma la idea de la Estética como una ciencia dedicada a las dimensiones sensoriales y rescata la concepción de "experiencia" de Jonh Dewey (1859-1952). La reflexión sobre la experiencia estética desde la perspectiva de la Somaestética propicia que los estudiantes y profesores valoren opciones culturales y artísticas más amplias considerando las experiencias estéticas más cercanas a la vida cotidiana y que se relacionan con placeres corporales.

PALABRAS-CLAVE

Cuerpo. Soma. Somaestética. Enseñanza del arte. Experiencia estética.

\section{Qual a arte ensinar?}

Concepções de arte estão presentes em todas as ações e instituições que promovem práticas artísticas e divulgam arte. Um grande espectro de práticas culturais coexistem no mundo contemporâneo e uma multiplicidade de práticas artísticas circulam em diferentes campos e sistemas de reconhecimento cultural. São inúmeras as experiências de grupos juvenis que se manifestam artisticamente, com identidades visuais, corporais e sonoras complexamente concebidas: skatistas, Straight edge, punks, hard core, heavy metal etc. Felizmente muitos centros culturais já têm assimilado tais práticas em suas programações, reconhecendo-as como legítimas. Nesse contexto, como posiciona-se o educador de arte? Ele sente-se preparado para reconhecer tais práticas e incluir as mesmas em suas aulas de arte, se sente seguro para defendê-las como legítimas? 
Pensar sobre o que é arte e porquê a arte deve existir, ou seja, pensar sobre concepções de arte e sobre como ocorrem experiências estéticas, não é um exercício abstrato e intelectual desvinculado das práticas educativas. São tais reflexões que orientam como a arte estará presente (como ação e reflexão) nos espaços de ensino. Pensar sobre a pertinência e a função da arte permite autonomia em relação às escolhas estéticas (de professores e estudantes) e deve constituir a formação de professores pois é fundamental na organização curricular de um curso. A reflexão filosófica acerca da arte orienta os discursos da arte e se traduz (intencionalmente ou não) na seleção de qual arte é apresentada nos museus e nos livros de arte, de qual arte é considerada nas políticas de atuação dos centros culturais e nos modos de avaliação de audiências e públicos (já que tais avaliações subentendem a valorização de uma certa experiência estética). Refletir sobre os princípios que regem e justificam a experiência estética auxiliam a pensar sobre o sentido social e cultural da arte. As questões que compõem a significância da arte devem ser trazidas para a superfície do ensino de arte e devem ser tematizadas com aprendizes.

Muitas instituições, ao naturalizar escolhas culturais regidas por determinadas concepções de arte, acabam por transmitir a falsa ideia de que só existe "uma arte" permanente e inquestionável a ser valorizada e divulgada. No caso específico do ensino de arte, ensinar a pensar a arte, ensinar a escolher as práticas artísticas ou reconhecer as experiências estéticas é mais importante do que ensinar sobre uma determinada arte "do além".

Se partimos do princípio de que a arte não tem um sentido permanente e ahistórico e que as práticas culturais sempre podem alterar tal sentido, podemos entender que as instituições de disseminação de arte têm um papel importante no processo de transformação legitimação e divulgação das ideias sobre arte, e assim o fazem. Locais de ensino de arte - a universidade, a escola, um pequeno museu, um centro cultural, uma galeria local - servem para transformar e ampliar a compreensão acerca da arte, para construir novas ideias sobre os sentidos da arte. São nesses espaços que muitas vezes se realizam as práticas que pedem novas definições, nominações, conceituações: sem perder de vista que práticas artísticas são tão 
mutáveis quanto todos os outros aspectos da vida humana -- da qual a arte depende para existir, uma vez que sem vida humana não existe arte.

Qual experiência estética pretende-se proporcionar? Qual arte ensinar? Qual o significado da arte para a vida das pessoas? De qual maneira a arte tem aplicabilidade ou pode melhorar a vida humana? Estas indagações, que compõem tanto a área de ensino de arte quanto políticas culturais, aprofundam a preocupação cognitiva de como se ensina/aprende arte, bem como apresentam outras questões relacionadas a qual arte se ensina/aprende, qual arte se transforma, ou ainda melhor: quais artes se aprendem, se transformam e se reconhecem no mundo contemporâneo.

Desta forma, apesar de o "significado da arte" ser um assunto complexo, e que pede a interlocução com outras áreas do conhecimento, ele deve ser assumido como um tema essencial para a área do ensino de arte, uma vez que é onipresente a qualquer ação educativa da arte. Tal significado está em constante transformação e pode ser refletido não somente a luz da tradição e das teorias da arte, mas também a partir de nossas práticas.

É neste sentido que apresento a perspectiva da Somaestética, que tem sua base na Estética (e não na Antropologia, Sociologia ou História) ou seja, trata prioritariamente da dimensão estética, do core da experiência artística. A Somaestética não determina ou explica uma concepção única de arte, mas concilia várias abordagens e defende uma maior consciência e transparência acerca dos fins da arte e de sua relação com a experiência somática.

De uma forma bem simples poderíamos dizer: na Somaestética a concepção da arte se constrói e se transforma a partir de como a arte é apreendida pelas pessoas (a partir da experiência); ou seja, é a experiência estética e de aprendizagem que também constrói a teoria da arte. Assim, pode-se pensar arte a partir de reflexões acerca de como os aprendizes praticam arte (que nos lembra a teoria do educador Paulo Freire). E, um educador de arte ou um produtor cultural não precisa se tornar um filósofo para poder discutir a arte que ele dissemina: ele pode situar-se neste amplo debate e refletir sobre a arte e os princípios estéticos que pretende promover ou transformar, através da sua prática. 
Neste sentido, de refletir acerca da arte disseminada e experenciada, a Somaestética apresenta uma abordagem apropriada para pensar experiências estéticas, (como o Congado e o Carnaval, por exemplo) presentes em contextos multiculturais contemporâneos, fora ou marginais ao mainstream da arte. Também as experiências estéticas que ocorrem em um circuito mais legitimado como as exposições promovidas pelos museus e galerias são igualmente consideradas, através da Somaestética, pois é possível pensar como os visitantes podem aproveitar melhor e mais integralmente uma visita à um museu, de forma a integrar esta visita em suas vidas.

\section{Origem da Somaestética: princípios da estética pragmatista}

A Estética Pragmatista foi criada por Richard Shusterman (SHUSTERMAN, 2014) há mais de vinte anos atrás. Apresentada de forma sistematizada em seu livro Pragmatist Aesthetics: Living Beauty, Rethinking Art" - tal publicação recebeu no Brasil uma tradução com o título "Vivendo a Arte: O Pensamento Pragmatista e a Estética Popular" (SHUSTERMAN, 1998). Uma das ideias centrais deste livro é a possibilidade de utilizar a noção de experiência estética como um princípio aberto, flexível e coerente para pensar sobre o significado da arte e das práticas artísticas. Tal proposta vislumbra um papel ativista de repensar a arte. Para sustentar tal proposição, o autor se baseia principalmente no conceito de experiência (estética) de John Dewey que ajuda a compreender práticas e experiências estéticas contemporâneas.

É fundamental a importância Dewey na Estética Pragmatista e sua atualidade para pensar questões acerca do Ensino de Arte. No Brasil, Ana Mae Barbosa já havia enfatizado a influência das ideias de Dewey no campo do Ensino da Arte do Brasil. Através do seu livro "Recorte e Colagem: Influências de John Dewey no Ensino de Arte no Brasil" publicado em 1982 (e com posterior edição ampliada "John Dewey e o ensino de arte no Brasil" em 2001), Barbosa (2001, p.15) não só apresenta o pensamento internacional de Dewey, como desenvolve análises históricas que destacam sua influência no ensino de arte nacional. Também, circunda um período no qual as ideias de Dewey, a partir, prioritariamente de compreensões simplistas e equivocadas, aliadas à uma política anti "Escola Nova" foram minimizadas. Talvez por 
esse "esquecimento" que uma das principais obras de Dewey no que se refere ao ensino de arte, Art as Experience, só foi traduzida e publicada no Brasil em $2010^{1}$.

A produção de Dewey, em um circuito mundial, no campo da estética e da arte, também foi encoberta por uma tendência dominante de teóricos que valorizavam ideias essencialistas ou "formalistas" de arte (SHUSTERMAN, 1992, p.4). Tais teorias dominantes, em geral se apoiam em uma visão de arte que defende a legítima experiência estética como aquela que, entre outras características, pressupõe desinteresse, e não tem nenhuma "utilidade" conectada com a vida. Nesse contexto, Shusterman colaborou para uma espécie de renascimento das ideias de Dewey (SHINER, 2001) no campo da Estética, num momento propício em que se vislumbravam tendências de mudança, visíveis através do surgimento de novas teorias e abordagens que valorizavam o contexto de produção dos objetos e que combatiam uma visão de arte permanente e rígida. Por exemplo, o livro de Vivendo a Arte escrito por Shusterman foi bastante divulgado pelo capítulo que tratava do movimento RAP, num período que tal movimento ainda não era parte do mainstream.

A ideia de se pensar arte a partir da experiência estética se opõe à uma tradição de pensar a arte a partir de objetos e produtos. Se olharmos para muitos livros de História da Arte, vemos uma sucessão de obras que explicam mudanças de estilos e movimentos artísticos, ou seja, mostram mais uma história das formas, das obras de arte, do que uma história das experiências estéticas que ocorreram face a tais produções artísticas. De modo geral, a estética pragmática se opõe a qualquer ideia "essencial" de arte ou às tais abordagens excessivamente formalistas. A presença da forma é considerada apenas um eixo na experiência; a importância da forma, em uma escultura por exemplo, se dá na medida em que ela suscita certa interação, motivação, sensações e sentidos. A forma, ou uma escultura, sozinha, em si, não é nada².

Alguns compêndios de História da Arte, por valorizar demais a forma pura e os objetos de arte, apresentam pouquíssimas discussões sobre as experiências que tais

\footnotetext{
Assim, é necessário ressaltar a importância dessa valorização de Dewey promovida pelo livro de Ana Mae Barbosa, 30 anos antes desta, entre os educadores.

2 É importante situar que tal visão formalista é diferente da concepção de formatividade apresentada por Pareyson (PAREYSON, 1993).
} 
obras de arte promoviam, quais eram seus públicos, qual era a interação destes públicos com os artistas, quais os cotidianos de produção, qual era o tempo e o espaço que a experiência estética ocupava na vida de diferentes públicos de arte e cultura. Ainda que os estilos estejam por vezes contextualizados, prepondera a crença no desenvolvimento autônomo da arte. Pensar a arte a partir da experiência estética que ela promove, ou tratar da experiência estética em conexão com a vida das pessoas, revela um sentido da arte em conexão com a vida e não autônoma a ela. Ademais, a ideia de que os artistas seriam profissionais autônomos gera consequências perversas, como: a)sem nenhuma amarra no tecido social os artistas se tornam facilmente dispensáveis; b) as questões econômicas e comerciais que envolvem a profissão do artista e que denunciariam sua dependência de uma estrutura social ficam encobertas sob a imagem de artista dandy que não precisa de dinheiro, remuneração ou relações de trabalho comuns. Tal falseamento de um vínculo social e econômico dos artistas, por um lado alimenta o glamour de poucos artistas bemsucedidos, por outro, provoca um cenário profissional completamente turvo para jovens artistas que nunca sabem como começar a ganhar dinheiro ou artistas que passam a vida inteira tentando ignorar a dimensão financeira de suas profissões (ARSLAN,2017).

A Estética Pragmatista oferece um caminho desobstruído que permite a compreensão contextualizada de muitas práticas culturais. No campo das Artes Visuais, a estética pragmatista serviu como base teórica para muitas pesquisas brasileiras sobre história em quadrinhos, vídeo clip, arte religiosa contemporânea, moda, entre outros assuntos ou práticas culturais, renegadas por teorias tradicionais da arte e que pedem uma abordagem não formalista e não essencialista da arte $^{3}$.

No caso de quem trabalha com a dimensão educativa da arte é fundamental a disponibilidade para compreender práticas artísticas diversas. Não podemos simplesmente ignorar as insistentes aparições de práticas artísticas funcionais ligadas ao entretenimento, assim como outros modos não institucionais de circulação da arte: em exposições de Shopping Centers, exposições em praças, escolas de ensino não

3 Quem me apresentou a teoria de, foi um pesquisador da área de História em Quadrinhos, o Doutor pela Universidade de Shusterman São Paulo, Gazy Andraus. 
- formal, pequenas escolas de pintura, só para citar alguns exemplos. A compreensão de práticas artísticas populares, sem uma antiguidade, e que não constam na historiografia da arte, ou que estão desconectadas de princípios estéticos dominantes é facilitada pelo escopo da Estética Pragmatista. Isso ocorre porque a Estética Pragmatista considera como legítimas muitas experiências estéticas que, por vezes, tem um caráter funcional, não estão comprometidas com o projeto moderno de inovação da linguagem.

No Brasil, museus de arte são escassos em muitas cidades distantes das capitais, e a experiência estética ocorre para além dos espaços institucionais da arte. Muitas práticas estéticas cotidianas dos brasileiros sugerem a conexão entre arte e vida e, para o ensino de arte, tais princípios da Estética Pragmática permitem um olhar mais inclusivo destas práticas culturais diversas que dominam a cena das escolas e centro culturais de centros urbanos e no interior.

É importante que se conceba um ensino de arte plural, não apenas relacionado à erudição ou a valorização de uma arte produzida por apenas um determinado grupo. Aprender arte, neste viés de relacioná-la com diferentes contextos e apoiada em uma visão pluralista, passa a ser importante porque exemplifica que a arte surge da vida e torna a vida melhor. Uma maior consciência acerca das experiências estéticas e perceptivas podem transmigrar de ambientes escolares para a vida cotidiana e vice e versa. Para tanto, faz-se necessário uma compreensão crítica acerca de muitas teorias da arte cujas bases estéticas foram edificadas em contextos de produção europeus, e por isso se referem e valorizam uma concepção de "belas artes" ou de uma "arte erudita".

A concepção de experiência estética, (assim como a concepção de arte), pode ser utilizada com sentidos e concepções bastante amplos que geram confusões e falta de entendimento. Shusterman aponta quatro dimensões principais, dentre as comumente associadas ao termo experiência estética: a) a dimensão avaliativa que associa a experiência estética à algum acontecimento importante e de valor; b) a dimensão fenomenológica que entende a experiência estética como algo vívido que, separado da cotidianidade, absorve sua atenção; c) a dimensão semântica que atribui à experiência estética uma experiência de grande significado que vai além de uma 
mera sensação; d) a dimensão delimitadora que define a experiência estética como algo "distinto" (que carrega atitudes próximas a que temos no campo da Arte).

Embora Shusterman não ache eficiente definir sua concepção do termo "experiência estética", ele apresenta várias imagens e exemplos da mesma, dentre as quais a metáfora para experiência estética como uma caixa de empatia (SHUSTERMAN, 2000). Esta caixa de empatia compreenderia experiências vívidas, que sugerem trânsitos e/ou transformações, proporcionam experiências compartilhadas, têm significado contextual, são intensas, podem ser prazerosas ou não e, finalmente, podem ocorrer em arte ou além da arte, (e isso não significa necessariamente que ocorra em toda a arte).

A noção de experiência estética de Shusterman se assemelha muito com a noção de Dewey de "experiência", veja Quadro Didático1:

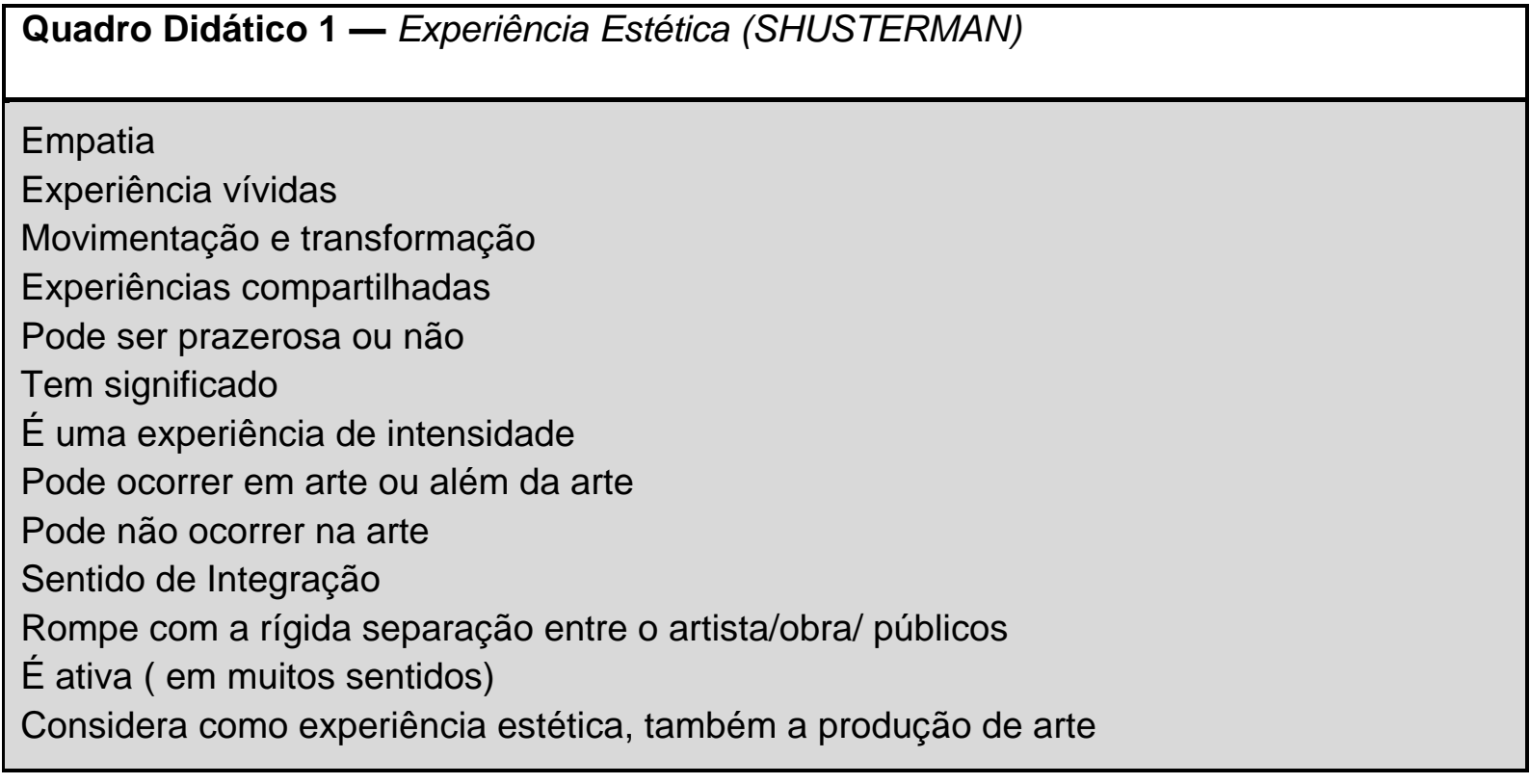

\section{Princípios da Somaestética}

O constructo teórico da Somaestética é praticamente um desdobramento da estética pragmatista. Se constitui como um campo de estudos interdisciplinar dedicado a pensar os aspectos somáticos das experiências estéticas, ou seja, centrase em pensar como o corpo(soma) é responsável por tais experiências estéticas que acontecem e podem melhorar a nossa vida. Na Somaestética a experiência estética 
é compreendida como uma experiência que não ocorre apenas na mente ou no cérebro (como se esses pudessem estar desligados do corpo). As experiências estéticas envolvem dimensões subjetivas e objetivas de um corpo vivo, que age, sente, com todos os seus sentidos integrados, um corpo que é ao mesmo tempo singular e inseparável do ambiente circundante.

Soma, presente no nome Somaestética, é o termo que se reporta a um corpo integral, que tem músculos, cérebro, ligamentos, órgãos, sensações, memórias afetivas, apetites, desejos etc. O soma inclui uma ampla compreensão "do corpo" em toda sua extensão, pois este depende de integração e conexão com o mundo circundante, interação com a temperatura, o ar, as emoções, as relações e associações sociais e todo o contexto do seu entorno. A concepção de soma é mais adequada para se referir à um "corpo vivo", já que a palavra "corpo" sempre está mais associada com "carne" ou a um corpo físico que estaria separado das ideias e fantasias. Para compreender melhor a diferença entre corpo e soma, podemos pensar que a palavra corpo pode até ser utilizada como sinônimo de cadáver, um "corpo" pode estar morto, ou ainda a palavra corpo é comumente utilizada em oposição à mente ou espírito, no senso comum. É por isso que no lugar de corpo, utiliza-se, ao longo deste texto, o termo soma ${ }^{4}$, porque para o soma, o corpo físico, a energia vital, a carne, os órgãos, as ideias, os impulsos instintivos, a inteligência e a memória são inseparáveis. Já a estética presente no nome Somaestética se relaciona com a estética pragmatista, que admite como legítimas as experiências estéticas que ocorrem numa relação direta com a vida, e que portanto dependem de uma relação somática, de um soma engajado, sensorial. Certa dimensão perceptiva e sensorial já se faz presente desde os princípios da disciplina Estética. Baumgarten propunha a "Estética", como um campo de estudos específico dedicado à experiencia sensorial. Nesse sentido, Shusterman atualiza tal ciência da "cognição sensorial" proposta por Baumgarten. Considerando que toda percepção sensorial depende do corpo, de suas ações e desejos, Shusterman incorpora ideias de Dewey (1859 -1952) e Wiliam James

4 O opção de escrever soma (corpo) e não somente o termo "soma" no início, se justifica pelo desejo de que o texto seja de leitura fácil e acessível, evitando assim terminologias específicas que podem interromper a fluidez da leitura. 
(1842 - 1910), que concordam que existe cognição nas faculdades do sentido do corpo e que o corpo aprende de forma inconsciente.

Então, a Somaestética junta tais conceitos (soma e estética) para constituir-se como um campo que se dedica ao estudo crítico de cultivo do soma visando ao aperfeiçoamento deste tanto para a vida quanto para suas diversas interações com a arte.

Ocorre que, numa certa tradição e linhagem da arte, passou-se a valorizar apenas a experiência estética mais relacionada com "distanciamento estético" (que é, de certa forma descorporificada). Nesta linhagem, excluíram-se muitas práticas artísticas mais engajadas e somáticas, que jogadas à escanteio são configuradas como "arte popular", ou são simplesmente desconsideradas como arte, justamente por enfatizarem prazeres somáticos (fazeres e fruições que priorizam os sentidos/estesia). É interessante observar que muitas das experiências estéticas excluídas da tradição das teorias da arte podem ser reconhecidas como legítimas sob o prisma da Somaestética. Por exemplo, muitas manifestações artísticas que servem aos prazeres da vida e do soma podem ser consideradas legítimas experiências estéticas se considerarmos a importância dos aspectos sensoriais e somáticos. Afinal, quais seriam os critérios para afirmar que prazeres, como os de participar de uma cerimônia religiosa, ou assistir uma partida de futebol são ilegítimos e superficiais ou que não possuem uma dimensão estética? O constructo da Somaestética nos permite estender a compreensão acerca dos prazeres e do conhecimento que pode surgir em tais experiências, uma vez que o princípio dominante que a Somaestética apresenta é que a experiência estética somática pode ocorrer em conexão aos prazeres "fugazes" do "corpo" ou atender funcionalmente às necessidades da vida cotidiana.

Isso significa que tais prazeres corporais são potentes e valiosos, contra uma longa tradição da área de Humanidades que encara o corpo apenas como objeto de distração das verdades, ou como objeto de manipulação, domínio e submissão ideológica. Também a cognição e o pensamento ocorrem integralmente no soma, ou seja, não há uma supervalorização da linguagem e do intelecto em detrimento do soma(corpo), aliás estão todos integrados. 


\section{Somaestética, ensino de arte e aprimoramento somático}

A intenção de aprimoramento somático é presente na Somaestética pois a ampliação de nossa apreciação sensorial ou ainda a melhora de nossas experiências estéticas e cognição decorrem de um melhor uso do nosso soma (e também o inverso).

Nosso desempenho em muitas ações da vida pode ser melhorado a partir da dimensão somática. Quando se trata de ensino e aprendizagem, a educação somática é essencial e deveria ser a base para que se realizassem as mais diversas atividades: com prazer, vitalidade, continuidade e atenção. Saber operar com o fluxo de nossa energia vital, controlar nosso tônus corporal (de um tônus mais alerta a outro mais passivo), ter repertório para mudar a postura e ritmo corporal de forma adequada (só para citar alguns exemplos), devem ser qualidades presentes em nossas ações de fazer, ver, ensinar e aprender arte. Da mesma forma, as experiências estéticas se admitidas como somáticas podem contribuir para a melhora de nosso soma.

O soma é o lugar onde expressamos nós mesmos através de nosso autocultivo, é através dele que formamos nosso estilo de vida e, consequentemente, nosso estilo de vida imprime em nosso corpo alguns modos de estar no mundo. Nosso desempenho depende deste soma: toda ação que propõem seu desenvolvimento possibilita não só o aumento de prazeres estéticos em ações pontuais, mas também melhora nossas ações cotidianas. Ao assumir tal proposição de aprimoramento e aplicação prática para a vida a Somaestética propõem uma conciliação e um caminho mediano através do qual as pessoas possam pensar suas vidas cotidianas e suas práticas estéticas dentro e fora das instituições de ensino e de disseminação da arte.

Todo o autoconhecimento somático não apenas ajuda as pessoas a terem uma performance mais ativa e consciente, mas também a melhorarem suas capacidades perceptivas em relação aos outros, a ficarem mais atentas às experiências estética e a identificar os desejos de outros somas. Felizmente, hoje, já se fala, no campo do ensino da arte, sobre estesia: educação dos sentidos. Práticas artísticas empobrecidas, (sem muita elaboração, estereotipadas e simplistas) tornam-se populares hoje exatamente porque a Arte se distanciou da vida cotidiana e se fechou em um discurso por vezes científico, de gênero acadêmico, e de difícil acesso para as 
pessoas (SHUSTERMAN, 2015). Uma grave consequência do discurso de autonomia da arte, é que ao separar arte e vida, separou também as grandes experiências (que podem ocorrer na arte) das pobres e duras experiências da vida.

A experiência estética apresentada pela Somaestética nasce do soma e tem também a capacidade de melhorá-lo. Ou seja, a Somaestética não somente ajudanos a compreender e desfrutar as experiências estéticas (através de uma consciência somática integrada) mas também defende que nosso soma pode ser aprimorado e transformado através das mesmas experiências estéticas. Essa característica de aperfeiçoamento pessoal apresentada pela Somaestética é uma das maiores contribuições para o campo do ensino da arte, pois traz para as experiências estéticas um objetivo de aprimoramento da nossa vida; de que contato com a arte pode nos fazer viver melhor.

A Somaestética, de certo modo, apenas revela e evidencia práticas que muitos já experimentam e sentem, mas que podem ser aprimoradas. Enfim, a gama de possibilidades que se abre é imensa diante da Somaestética. Segue quadro didático com alguns conceitos-chave:

Quadro Didático 2 - Somaestética: Princípios fundamentais

\begin{tabular}{|l|l|}
\hline $\begin{array}{l}\text { Aprimoramento } \\
\text { somático e } \\
\text { funcionalidade }\end{array}$ & $\begin{array}{l}\text { Através das experiências estéticas, podemos ampliar nossos } \\
\text { sentidos e assim melhorar muitas outras dimensões de nossas vidas. }\end{array}$ \\
\hline $\begin{array}{l}\text { O soma como } \\
\text { compreensão } \\
\text { integrada do } \\
\text { corpo vivo }\end{array}$ & $\begin{array}{l}\text { O soma não acaba no invólucro de nossa pele, mas compreende } \\
\text { uma visão integral, onde é impossível separar corpo e meio } \\
\text { ambiente, o corpo e seu contexto (por exemplo: nós somos o que } \\
\text { comemos e o que comemos transforma toda a paisagem). }\end{array}$ \\
\hline $\begin{array}{l}\text { A aceitação dos } \\
\text { prazeres corporais } \\
\text { como experiência } \\
\text { válida e cognitiva }\end{array}$ & $\begin{array}{l}\text { Assumir que o soma não é apenas distração do pensamento: ele é } \\
\text { parte do nosso processo de aprendizagem e reflexão. }\end{array}$ \\
\hline
\end{tabular}

Sentir e fazer arte estão relacionados à aspectos sensoriais. A capacidade de reconhecer as sensações, a estesia, é essencial para que se efetive uma experiência estética. Assim, a auto-observação, o cuidado de si, a identificação das dimensões 
sensoriais, são imprescindíveis para que se efetivem as experiências estéticas e, portanto, devem ser consideradas como essenciais para os ambientes de ensino aprendizagem com arte.

Pensar na coluna vertebral, nos espaços entre as vértebras ou na movimentação sutil do tórax, movimentar-se com a consciência do espaço, respirar profundamente não são ações desconectadas de nossa vida: destas ações principiam também as experiências estéticas. A experiência estética nasce no soma. Quanto maiores nossas capacidades de sentir, mais sentiremos.

\section{Referências}

ARSLAN, L.M. Formação e trabalho em artes visuais: a sobrevivência do artista. In: ARSLAN, L.M.; Melo, R.M (org). Artes visuais e educação: ensino e formação. Uberlândia: EDUFU, 2007.

PAREYSON, L. Estética: Teoria da formatividade. Petrópolis, RJ: Vozes, 1993.

SHINER, L. La invención del arte: una historia cultural. Madrid: Paidós, 2001.

SHUSTERMAN, R. Arte e Religião. Revista Redescrições - Revista online do GT de Pragmatismo e Filosofia Americana da ANPOF. Ano 3, Número 3, 2012. Disponível em: <http://www.gtpragmatismo.com.br/redescricoes/edicao1_2012.html>. Acesso em: 19 dez. 2018.

SHUSTERMAN, R. The invention of Pragmatist Aesthetics: Genealogical Reflections on a notion and a name. In: MALECKI, W. Practicing Pragmatist aesthetics: critical Perspectives on the Arts. AmsterdamNew York: Editions Rodopi B.V, 2014.

SHUSTERMAN, R. Vivendo a arte: o pensamento pragmatista e a estética popular. São Paulo: Editora 34, 1998.

SHUSTERMAN, Richard. Performing life: aesthetic alternatives for the ends of art. New York: Cornell University Press, 2000.

SHUSTERMAN, Richard. The MWS Podcast 67: Richard Shusterman on Somaesthetics and the Middle Way. The Middle Way Society, 2015. Podcast. 01:07:56. Disponível em: $<$ http://www.middlewaysociety.org/the-mws-podcast-67-richard-shusterman-on-somaesthetics-and-

the-middle-way/>. Acesso em: 11 nov. 2018.

\section{Luciana Mourão Arslan}

É professora na Universidade Federal de Uberlândia, na graduação em Artes Visuais, e graduanda no curso de Bacharelado em Dança. Tem vários livros publicados, incluindo uma obra didática aprovada no PNLD. Concluiu em 2015 pesquisa pós-doutoral no Center for Body, Mind and Culture na Florida Atlantic University - FAU, Estados Unidos, (com bolsa da CAPES) e realizou estágio na Universitat de Barcelona (com bolsa Santander) durante seu doutorado. Desenvolveu o projeto de pesquisa e extensão Yoga no Museu (com apoio FAPEMIG) e atualmente desenvolve Yoga no Santa.Suas pesquisas investigam as relações entre o soma e experiência estética (Somaestética). É líder do grupo SOMA (antigo somaestética) e participante do grupo NEID que estuda improvisação em dança.

Email: lucianaarslan@gmail.com

Currículo: http://lattes.cnpq.br/5399813319581612

Recebido em 8 de setembro de 2018

Aceito em 10 de novembro de 2018 